\title{
Stimulus control by response-dependent shock in discriminated punishment
}

\author{
R. G. WEISMAN \\ Queen's University at Kingston, Kingston, Ontario, Canada
}

\begin{abstract}
Two pigeons keypecked on a multiple schedule of discriminated punishment. A white line on a green surround was associated with variable interval reinforcement and electric shock following each response, and the green surround alone was associated only with variable-interval reinforcement. When the white line was on, the key responding was suppressed. Probe presentations of the white line alone and the punishment contingency alone, and sessions under a mixed schedule of punishment without the white line, showed that response dependent shock controlled responding to a much greater degree than its putative discriminative stimulus. The results are seen as an instance of overshadowing of a correlation between a stimulus and shock by a more immediate and reliable correlation between a response and shock.
\end{abstract}

In mixed (mix) schedules of punishment, stimuli are not explicitly associated with the presence or absence of response dependent electric shock. It is well known that the response-shock contingency can function as discrimination for further food or shock resulting in differential performance to the two components of the mixed schedule (Azrin \& Holz, 1966, pp. 418-424). Discriminated punishment procedures are multiple schedules that alternate an explicit discriminative stimulus, $\mathrm{S}^{\mathrm{D}}$, associated with response-dependent shock and reinforcement, with a stimulus associated only with reinforcement. Given the relative ease with which a regular response-shock contingency controls responding in mixed schedules, it is rather odd that the discriminative function of this contingency in multiple schedules of discriminated punishment is so often ignored. In the present experiment, reduced responding in the presence of a visual $S^{D}$ for punishment provided no reassurance that the visual $S D$ and not the punishment contingency itself controlled responding.

\section{METHOD}

\section{Subjects}

Two adult male Silver King pigeons with extensive experimental histories were maintained at $80 \%$ of their free feeding weights.

\section{Apparatus}

A standard pigeon chamber was modified to deliver electric shock via wing clips (Hoffman \& Fleshler, 1965). The reinforcer was $5-\mathrm{sec}$ access to mixed grain, the punisher was 3-mA, 150-msec shock.

\section{Procedure}

The birds had 21 sessions with a mult VI 5-min VI 5-min schedule. The first component correlated with presentation of a green surround on the key had a fixed time of $1 \mathrm{~min}$. The second

This research was supported by grants from the National Research Council of Canada and the Ontario Mental Health Foundation. This manuscript was prepared while the author was a Visiting Professor at the University of Sussex, England, supported by a Canada Council Leave Fellowship. Reprints may be obtained from R. G. Weisman, Department of Psychology, Queen's University, Kingston, Ontario, Canada. component correlated with a white line on the green surround had a variable time averaging $5 \mathrm{~min}$. The two components simply alternated in each cycle of the multiple schedule. Separate and independent film tapes scheduled reinforcement in each component. Reinforcements scheduled but unearned in one component were cancelled with the onset of the other component.

The multiple schedule continued as before but electric shock followed every response in the second component, associated with the white line, mult VI 5-min VI 5-min + pun, for nine sessions. In Session 31, the birds had four probes for stimulus control: two "line only" 1-min presentations of the second component with the associated white line but without response dependent shock; two "response dependent shock only" 1-min presentations of the second component with response dependent shock but without the white line. Other presentations of the

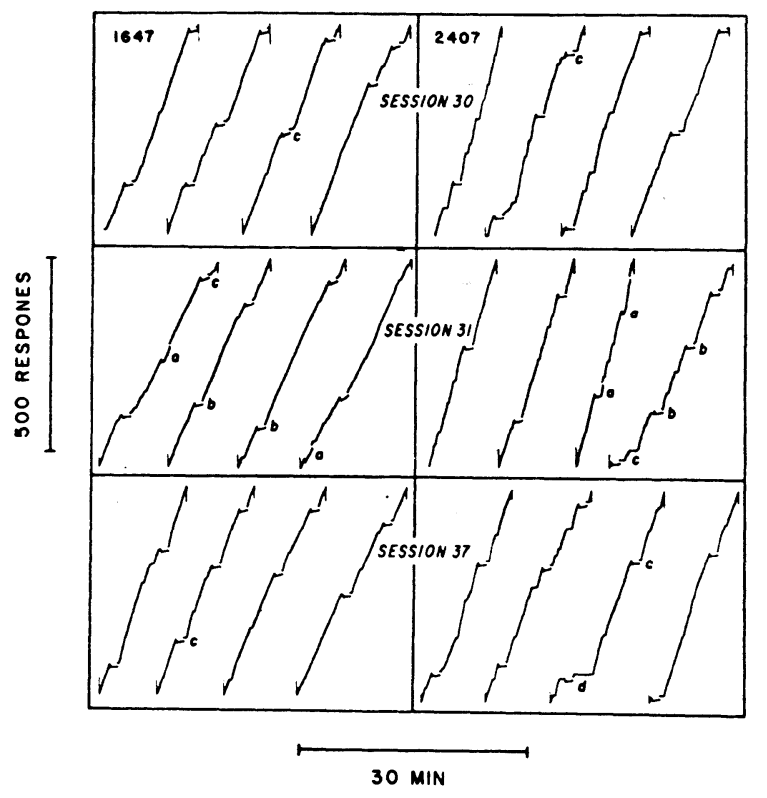

Figure 1. Cumulative response of a multiple schedule of discriminated punishment (Sessions 30 and 31 ) and a mixed schedule of punishment (Session 37). Details shown at " $a$ " are stimulus alone and at " $b$ " punishment alone probes; details shown at " $c$ " and "d" are pauses following the offset of the punishment component. 
second component were as in the nine previous sessions. After Session 31 , the birds had six additional sessions with response dependent shock but without the white line, mix VI 5-min VI 5 -min + pun.

\section{RESULTS}

The upper panels of Figure 1 show cimulative response records for mult VI 5-min VI 5-min + pun in Session 30. The response pen was offset downward during the punishment component of the schedule. Responding was suppressed by frequent long pauses separated by very short bursts of responding in this second component. Also, responding in the first component tended to resume after a pause rather than immediately at the end of the second component (see components marked "c").

The middle panels show results for stimulus control probes in Session 31. Both birds responded at a lower rate early in the first "line only" stimulus probe, but at much higher rates later in that probe and throughout the second "line only" probe (both probes are marked as "a"). Responding during the "response dependent shock only" probes, marked as " $b$," was indistinguishable from that seen during unprobed punishment components.

The lower panels show final performance with mix VI 5-min VI 5-min + pun. These cumulative response records bear a striking resemblance to those of multiple schedule performance shown in the upper panels. Pauses following the punishment component continued, but Bird 2407 showed an increase in pauses not associated with the punishment component (example at " $d$ ").

\section{DISCUSSION}

The present experiment found control of suppression by the visual $\mathrm{S}^{\mathrm{D}}$ alone in the "line only" probes minimal. Perhaps whatever little control the visual $S^{D}$ engendered extinguished in the early seconds of the first probe. In contrast, stimulus control by punishment alone in the "response dependent shock alone" probes, and in the mixed schedule, was equal to that engendered by the visual $S^{\mathbf{D}}$ plus punishment in the multiple schedule.

Of course, in many experiments, the precise stimuli or stimulus dimensions controlling performance in multiple schedules are unknown. Often the interpretation of an experiment is not clouded seriously by confounding, say, the wavelength and intensity dimensions of visual discriminative stimuli associated with the components of a multiple schedule.
However, confounding of control by the punishment procedure itself with putative control by the stimuli associated with a regular response-shock contingency has complicated the interpretation of discriminated punishment experiments.

There is evidence which strongly suggests that control by the visual $S^{D}$ for punishment was not weakened by the discriminative function of shock per se but by the discriminative function of the response-shock contingency. When Orme-Johnson and Yarczower (1974) compared discriminated punishment with a yoked procedure (Pavlovian conditioned suppression), the Pavlovian CS suppressed responding to zero and was an effective conditioned punisher, but the $S^{D}$ for punishment controlled less suppression and was not an effective conditioned punisher. Even more important in this context, when presented without shock, as in the probe session of the present experiment, the Pavlovian visual $C S$ suppressed responding and visual $S^{D}$ for punishment did not. Since shock occurred with the same distribution in the visual stimulus in each procedure, the response-shock contingency and not shock alone must account for the difference in the effectiveness of the visual stimulus.

The origin of this difference is not difficult to discern. In the Orme-Johnson and Yarczower study and the present work, the pigeon's peck bore a more immediate and reliable relationship to shock than the visual $S^{D}$ and thus the former association overshadowed (Miles \& Jenkins, 1973; Wagner, 1969) the latter. But the opposite can also occur. Mackintosh (1974, pp. 220-221) reported an experiment by St. Claire-Smith in which a briefly presented stimulus regularly associated with the response producing shock overshadowed the response-shock association. As Mackintosh pointed out, the immediacy reliability and salience of the events correlated with shock determine their eventual control over responding.

\section{REFERENCES}

Azrin, N. H., \& Holz, W. C. Punishment. In W. K. Honig (Ed.) Operant behavior: Areas of research and application. New York: Appleton-C'entury-Crofts, 1957.

Ferster, C. B., \& Skinner, B. F. Schedules of reinforcement. New York: Appleton-Century-Crofts, 1957.

Hoffman, H. S., \& Fleshler, M. Stimulus aspects of aversive controls: The effects of response contingent shock. Journal of the Experimental Analysis of Behavior, 1965, 8, 89-96.

Mackintosh, N. J. The psychology of animal learning. London: Academic Press, 1974.

Miles, C. G., \& Jenkins, H. M. Overshadowing in operant conditioning as a function of discriminability. Learning and Motivation, 1973, 4, 11-27.

Orme-Johnson, D. W., \& Yarczower, M. Conditioned suppression, punishment, and aversion. Journal of the Experimental Analy sis of Behavior, 1974, 24, 57-74.

Wagner, A. R. Stimulus validity and stimulus selection in associative learning. In N. J. Mackintosh and W. K. Honig (Eds.) Fundamental issues in associative learning. Halifax: Dalhousie University Press, 1969, 90-122.

(Received February 18, 1974.) 